\title{
DEBATES SOBRE A CULTURA EM PORTUGAL O complexo caso do livro e da leitura
}

\author{
Daniel Melo \\ CHAM, FCSH, Universidade NOVA de Lisboa, Lisboa, Portugal
}

Resumo Neste texto problematiza-se o livro e a leitura à luz dos debates centrais ocorridos no Portugal novecentista. Procedeu-se à caracterização dos principais atores individuais e coletivos envolvidos, não só nos debates como na ação cultural para aquelas áreas, e dos seus legados mais relevantes, a partir dum quadro teórico que preconiza a noção de política cultural alargada, envolvendo estado e sociedade civil organizada. Analisaram-se discursos e iniciativas representativas, os quais estiveram em sintonia com os debates internacionais. Foram estes contributos decisivos para mudanças marcantes, apesar das limitações impostas (em especial pela longa ditadura): a uma perspetiva de doutrinação e qualificação técnica para o trabalho foi-se sobrepondo gradualmente uma perspetiva aberta, plural e formativa do cidadão integral, promotora da democratização cultural, da coexistência de visões e da bibliodiversidade.

Palavras-chave: democratização cultural, política cultural, livro, leitura, edição.

\section{Debates on culture in Portugal: the complex case of book and reading}

Abstract This text problematises the question of books and reading in the light of the key debates that took place in 20th-century Portugal. It characterises the main individual and collective actors involved not only in the debates themselves, but also in the cultural action in those areas, as well as their most important legacies, based on a theoretical framework that advocates the notion of a broad cultural policy involving both the state and organised civil society. The author analyses a number of representative discourses and initiatives, which were in line with the debates in other countries. Despite the limitations imposed on the participants (especially by the long-lived dictatorship), they made decisive contributions to some major changes: a perspective that emphasised indoctrination and technical qualification for work was gradually replaced by an open, plural perspective seeking the formation of the complete citizen and promoting cultural democratisation, the coexistence of different views and bibliodiversity.

Keywords: cultural democratization, cultural policy, book, reading, publishing.

Débats sur la culture au Portugal: le complexe cas du livre et de la lecture

Résumé Ce texte problématise le livre et la lecture à la lumière des débats centraux qui ont été menés au Portugal au XXe siècle. Il procède à la caractérisation des principaux acteurs individuels et collectifs impliqués non seulement dans ces débats mais aussi dans l'action culturelle, ainsi qu'à celle de leurs principaux héritages, à partir d'un cadre théorique qui préconise la notion de politique culturelle élargie, impliquant l'État et la société civile organisée. Il analyse également les discours et les initiatives représentatives qui se faisaient l'écho des débats internationaux. Ces contributions furent décisives pour les changements marquants, malgré les limitations imposées (en particulier par la longue dictature) : l'approche d'endoctrinement et de qualification pour le travail est peu à peu supplantée par une approche ouverte, plurielle et formative du citoyen à part entière, propice à la démocratisation culturelle, à la coexistence de visions et à la bibliodiversité.

Mots-clés: démocratisation culturelle, politique culturelle, livre, lecture, édition.

\section{Debates sobre cultura en Portugal: el complejo caso del libro y la lectura}

Resumen En este texto se problematiza el libro y la lectura a raíz de los debates centrales ocurridos en el Portugal novecentista. Se procedió a la caracterización de los principales actores individuales y colectivos involucrados, tanto en los debates como en la acción cultural para aquellas áreas, y de sus legados más relevantes, a partir de un marco teórico que defiende la noción de política cultural extendida involucrando estado y sociedad civil organizada. Se analizaron discursos e iniciativas representativas, los cuales estuvieron en sintonía con los debates internacionales. Fueron estas contribuciones decisivas para cambios importantes a pesar 
de las limitaciones impuestas (especialmente por el largo periodo de la dictadura): de una perspectiva de adoctrinamiento y calificación técnica para el trabajo se fue sobreponiendo gradualmente una perspectiva abierta, plural y formativa del ciudadano integral, promotora de la democratización cultural, de la coexistencia de visiones y de la bibliodiversidad.

Palabras-clave: democratización cultural, política cultural, libro, lectura, edición.

No Portugal do século XX, o debate público sobre o livro e a leitura esteve sempre muito condicionado pela questão educativa e pela questão do gosto. No presente texto proponho analisar esta problemática à luz dalguns dos principais debates ocorridos, uns mais circunstanciais, outros mais duradouros. Para facilidade de exposição dividi-o em cinco partes: ${ }^{1}$

1) articulação entre educação e cultura para o aperfeiçoamento da pessoa;

2) escola, política patrimonial-custodial e ensino seletivo $v s$. campanhas de alfabetização e qualificação, bibliotecas para todos e assunção estratégica pelo estado da massificação do ensino;

3) democracia e democratização culturais: do endoutrinamento e formação técnica para o trabalho a uma perspetiva aberta, plural e formativa do cidadão integral;

4) debates sobre o papel da leitura: entre informação, formação e recreação;

5) outros debates ligados à maior riqueza de opções.

Esta análise tem subjacentes quatro dimensões teóricas principais que importa desde já explicitar. Em primeiro lugar, o recurso à noção de política cultural alargada (estado e sociedade civil organizada) e inclusiva (apud Canclini, 2001), que abre para o estudo do contributo dos estados e de organizações especializadas (nacionais, internacionais e transnacionais) na elaboração de políticas culturais em cada país e em movimentos e arenas internacionais.

Em segundo lugar, o recurso à história das bibliotecas em perspetiva comparativa, permitindo perceber o impacto da cisão entre políticas patrimoniais e de democratização do acesso ao livro e à leitura no quadro histórico europeu, e delimitar a centralidade internacional do modelo anglo-saxónico da "biblioteca para todos" (public library), na perspetiva avançada por autores como Traniello (1997) e Maurel (2011).

Em terceiro lugar, o recurso à abordagem das transferências culturais e dos processos de cruzamento (apud a corrente da histoire croisée), que permite o estudo de fenómenos culturais em cada contexto eleito para estudo, seja uma comunidade, uma rede institucional, um dado território, etc. (Lingelback, 2011; Werner e Zimmermann, 2006). Tal dimensão recusa uma lógica difusionista e redutora, no sentido duma mera relação unidireional, entre um "emissor" todo-poderoso e um "recetor"

1 Este trabalho é financiado por fundos nacionais através da FCT - Fundação para a Ciência e a Tecnologia, I.P. — , no âmbito da norma transitória DL 57/2016/CP1453/CT0062. 
passivo. Ao invés, o cerne está na interação, na adaptação e nas dependências mútuas (sobre o tema $v d$. ainda Shep, 2008).

Em quarto lugar, o recurso à teorização em torno da democratização cultural e da democracia cultural (esta sendo o fito daquela), a qual procura clarificar o quadro conceptual mais lato, a génese histórica dos conceitos implicados e das práticas, os processos socioculturais e político-culturais e as tendências institucionais no contexto dum debate teórico inacabado e complexo. ${ }^{2}$ Tal reflexão permite clarificar o cerne das políticas culturais, os condicionamentos socioeconómicos, o papel historicamente central do estado, o nexo com os direitos humanos, a importância da emancipação das sociedades e dos cidadãos, bem como o seu nexo com a questão da massificação. A massificação da cultura empreendida pela indústria cultural de massas não é sinónimo de democratização ou democracia cultural, pois só estas visam o acesso de todos à generalidade dos bens culturais (e também à criação), permitindo assim que se possam construir repertórios de escolhas individuais e coletivas e que se possa aceder a uma variedade cultural não contemplada pela indústria cultural de massas tal como se encontra configurada nos territórios a que pode aceder cada cidadão num dado momento. Uma política cultural democrática implica, portanto, uma democratização cultural mínima. A massificação da cultura distingue-se da massificação do ensino na medida em que esta última foi, regra geral, fornecida pelo estado, e envolve um serviço (formação / escolarização) e não bens ou obras (culturais ou escolares).

Outras dimensões teóricas importantes, mas suscitadas pelos próprios debates culturais, serão analisadas no decurso do texto, tais como a articulação entre educação e cultura, e os regimes da edição da comunicação e a "morte do livro".

\section{Articulação entre educação e cultura para o aperfeiçoamento da pessoa}

Um dos debates mais recorrentes foi o da junção entre educação e cultura para o aperfeiçoamento da pessoa: o progressismo avançou nesse domínio por intermédio das sociedades educativo-culturais, dos centros republicanos e das universidades populares e livres, mas a falta de bases sólidas levantou amiúde a questão do papel do estado.

Com efeito, nos séculos XIX e XX, a falta de oferta pública educativa e cultural a um preço acessível para a maioria da população levou setores da sociedade civil organizada a criar alternativas concretas, por impulso do seu ideário e abarcando correntes distintas - anarquistas, republicanas, católicas, "basistas", etc. Todavia, em muitas áreas e conjunturas, estas alternativas não conseguiram oferecer uma cobertura universal, minimamente alargada ou duradoira. Daí também a necessidade de "mais estado" (para uma parte gradualmente maior da sociedade). Seja como for, essas iniciativas tiveram três efeitos relevantes:

2 V.g., Costa (1997), Santos (1998), Canclini (2001), Lopes (2007) e Maraña (2010). 
1) impuseram a ideia de que a educação (escolar mas não só) devia articular-se com a cultura, ou seja, a formação escolar é indispensável para a formação e desenvolvimento cultural do indivíduo e das populações;

2) mostraram que são necessárias estruturas robustas e de projeção nacional, do livro às artes, envolvendo distintas entidades e as comunidades locais;

3) legaram um potencial valioso de criatividade, experimentação, sinergias em várias áreas, plasmado em equipamentos coletivos, em iniciativas locais / comunitárias (bibliotecas, animação cultural, dinamização da leitura, encontros com escritores, fomento da literatura infanto-juvenil, ensino artístico, etc.) e no próprio debate de ideias.

Trata-se dum debate abrangente e com conexões a outros, devido à mesma influência central das conceções de educação e cultura na formulação de políticas e iniciativas concretas. ${ }^{3}$

\section{Educação seletiva e política patrimonial-custodial vs. educação e bibliotecas para todos}

Não foi uma evolução fácil e linear; para uma boa parte da intelectualidade, mesmo a republicana, a prioridade até muito tarde foi a criação dum escol e as bases duma política patrimonial e custodial, que articulasse museus, arquivos e bibliotecas. Esta perspetiva tem o seu pico na I República, com a criação de duas redes nacionais estatais específicas, de âmbito distrital (bibliotecas e arquivos, por um lado, museus por outro, ambas incompletas), e com a aposta na educação secundária e superior, ainda que valorizando também o ensino primário, o que na época significaria um maior estímulo para um segmento modesto da população, por razões socioeconómicas. ${ }^{4}$

A I República não foi só conservacionista e elitista; também desenvolveu medidas potencialmente democratizantes, como o planeamento, o alcance territorial nacional (metropolitano) dum conjunto de bibliotecas contemplando os principais públicos e grupos sociais. A "biblioteca para todos", que aí começou a entrever-se (se sobrepusermos certas tipologias e na lógica da novel Biblioteca Popular de Lisboa) teve um longo caminho para se afirmar no país, precisando de acumular lições, como a necessidade de articular estado central com municípios e comunidades locais, numa lógica inclusiva, de longo prazo e de âmbito nacional. Embora imperfeita e já finda, foi marcante a experiência das bibliotecas itinerantes e fixas da Fundação Calouste Gulbenkian (FCG), surgidas em 1958. Deram um forte impulso à criação de hábitos de leitura disseminados por todo o país, em especial junto do público infanto-juvenil, diversificaram a oferta livreira e difundiram uma perspetiva positiva, menos constrangida e

3 Este debate, com desdobramentos em iniciativas oficiais envolventes, como o Plano Nacional de Leitura (que se refere infra), foi aflorado por vários autores: v.g., Dionísio (1993), Fernandes (1993), Santos (1998), Teodoro (2001), Candeias (2004 e 2005), Lopes (2004), Melo (2004, 2008 e 2010), Lourenço (2010), e Alçada (2016)

$4 \quad$ Melo (2004 e 2010), Ribeiro (2008). 
formal do livro e da leitura, a começar no seu boletim. O debate na imprensa também ajudou (Melo, 2004 e 2010).

Entre aqueles que pugnaram pelo alargamento da leitura, cabe destacar grupos ligados a revistas de reflexão e a organizações socioprofissionais do setor ( $v$ d. seleção representativa no quadro 1). A maioria dos intelectuais e especialistas foi desafeta à ditadura ou mesmo antissalazarista. Muitos apoiaram-se em documentos internacionais, sobretudo no manifesto A Biblioteca Pública, Força Viva ao Serviço da Educação Popular (da UNESCO e da International Federation of Library Associations and Institutions [IFLA], de 1949), para defender vias democratizantes nesta área. Através dessas bibliotecas, grandemente inspiradas no modelo anglo-saxónico da public library, aceder-se-ia gratuitamente a um acervo generalista e sem censura de correntes filosóficas, políticas, religiosas, estéticas, etc., criando assim novos espaços educativos. ${ }^{5}$

Ligado ao regime salazarista refira-se Veiga de Macedo, mormente pelo seu contributo para o Plano de Educação Popular. Ressalve-se que foram vários os apologistas eleitos que, a dado momento do seu percurso, exerceram cargos públicos, sobretudo em postos de direção técnica na administração pública. ${ }^{6}$ Em 1983, aquele documento da UNESCO e da IFLA inspirou os bibliotecários portugueses no seu manifesto A Leitura Pública em Portugal, pressionando pela reforma do setor, em crise profunda devido à falta de interesse público, ao atraso e ao mau serviço prestado pelas bibliotecas públicas, à falta de articulação com a rede da FCG, aos altos níveis de iliteracia, etc. ${ }^{7}$ O volta-face viria em 1986/87, com a assunção pelo estado duma rede pública de bibliotecas para todos, herdando e renovando a estrutura das bibliotecas da FCG, concebidas pelo escritor e dinamizador cultural Branquinho da Fonseca. A hoje conhecida como "rede de leitura pública", formada por 158 bibliotecas municipais (em 2008), foi a mais consensual das iniciativas recentes na área do livro e da leitura, ainda que sendo cunhada como "revolução silenciosa e tranquila" (Nunes, 2008). E foi a mais democratizante: a biblioteca generalista firmou-se então como centro polivalente e comunitário de cultura, integrando as comunidades, dando-lhes ferramentas para as várias literacias e expectativas culturais, aproximando-os dos escritores e outros artistas nas sessões com autores, exposições, hora do conto e/ou de animação da leitura, acolhendo os avanços da animação cultural, etc. Também foi consensual a criação duma rede de bibliotecas escolares, lançada em 1996, bem avaliada (estudo do CIES-ISCTE de 2009, vd. Costa et al., 2010) e atualmente com duas mil bibliotecas servindo dois milhões de

5 Traniello (1997: 283-297 e 359-361). A revisão de 1972 pôs estas bibliotecas ao serviço da educação, cultura e informação, com abrangência territorial (implicando meios complementares, como bibliotecas ambulantes) e inscrição local ("centro cultural da comunidade"), cooperação entre pares e financiamento público (IFLA, 1988). Anunciou a nova "biblioteca plurifuncional", espaço de inovação e de animação culturais, atenta à extensão/ação cultural (Bettega, 2008: 65-67). A revisão de 1994 concebeu a biblioteca pública enquanto "centro local de informação" que fornece "todo o tipo de informação e conhecimento" a todos, implicando a presença das novas tecnologias de informação e comunicação e a promoção da herança cultural, das artes e da ciência (IFLA, 2016).

6 Na divulgação releve-se ainda Eduardo Prado Coelho (2004). Nos seus textos de imprensa, Branquinho da Fonseca remete para uma obra patrocinada pela UNESCO, L'Extension des Bibliothèques Publiques, de Lionel R. McColvin, uma de várias alusões a esta organização intergovernamental dedicada à educação, ciência e cultura.

$7 \quad$ Nunes (1996: 31, 58 e 77-79). 
estudantes (Beja, 2012: 78-82). Esta rede foi articulada com um Plano Nacional de Leitura (PNL), ativo desde 2006 e que se tornou desde então no instrumento de referência da política pública para o reforço das práticas de leitura e das literacias digital e de leitura (e também para o fomento do livro, pelo seu forte impacto em aquisições e na visibilidade de certas obras). Dado o universo potencial - todos os estudantes do ensino básico -, tornou-se uma oportunidade de democratização da leitura, dando seguimento a certas conceções e debates (como o da articulação entre educação e cultura, a relevância da promoção da leitura) e creditando a liderança e experiência de atores antes presentes noutros marcos). ${ }^{8}$

No quadro de prioridades limitadas pelas debilidades económicas e políticas dum país semiperiférico, e pelas conceções elitistas, a desvalorização da educação de massas foi contrabalançada por cíclicas campanhas em prol da alfabetização e duma sociedade mais qualificada, culminando numa assunção estratégica pelo estado duma massificação do ensino, ainda que incompleta e criticada por certos setores. ${ }^{9}$

No debate sobre o alargamento do acesso à cultura tem sido consensual a necessidade de expandir o ensino no país, dada a correlação entre capitais escolar e cultural. Nesse ponto, o ensino básico regular foi prioridade e deu frutos (Teodoro 2001). Em contrapartida, faltou "vontade política para adotar a educação e formação de adultos como instrumento estratégico para uma sociedade mais avançada e equilibrada". Apesar do progresso educativo notório no último quarenténio, persistem em Portugal 500 mil analfabetos (Censos de 2011) e 60\% da população ativa não tem qualificação secundária ou superior (para uma média de $23 \%$ na União Europeia). $\mathrm{Na}$ "ausência de uma educação generalizada" não só se agrava a exclusão social e "crescem as desigualdades de toda a natureza" como se perde a perspetiva humanista na educação de adultos. ${ }^{10}$ Ou seja, a prevalência duma perspetiva instrumental, centrada na qualificação profissional, erodiu as dimensões que mais afloraram no pós-revolução por obra do associativismo voluntário e do estado central: a educação popular e cívica, a "educação comunitária e para o desenvolvimento local, numa valorização da emancipação e da criatividade", tanto individual quanto coletiva. ${ }^{11}$ Estas dimensões tenderam, gradualmente, "a ser recusadas ou, sendo toleradas, a atribuir-[se]-lhes um estatuto periférico em termos de políticas públicas e um mais baixo status em termos socioeducativos". ${ }^{12}$

8 Casos de Isabel Veiga / Isabel Vilar / Isabel Alçada e de Teresa Calçada (vd. quadro 1 e Alçada, 2016). Realce-se que o nexo educação-cultura esteve presente no lançamento da rede de bibliotecas escolares, na articulação institucional entre ministérios da Cultura e da Educação e no seu fito abrangente e integrador de vários recursos e competências: "instalar e desenvolver bibliotecas em escolas públicas de todos os níveis de ensino, disponibilizando aos utilizadores os recursos necessários à leitura, ao acesso, uso e produção da informação em suporte analógico, eletrónico e digital" (http://www.rbe.mec.pt/np4/programa.html).

9 Teodoro (2001), Candeias (2004 e 2005: 53-113).

10 Citações e dados extraídos de comunicado recente duma associação representativa desta área (vd. Associação Portuguesa para a Cultura e Educação Permanente: APCEP, 2016).

$11 V d$. Távora, Vaz e Coimbra (2013: 25).

12 Cit. de Licínio Lima, Educação ao Longo da Vida, São Paulo, Cortez Editora, 2007, p. 9 (cit. em Távora, Vaz e Coimbra, 2013: 25). 


\section{Entre democratização e democracia culturais}

A democratização cultural também foi um tema muito discutido, sobretudo após a II Guerra Mundial. Subjazia-lhe amiúde a democracia cultural, o que se tornou mais explícito após o derrube da ditadura. Naquele âmbito, oscilou-se entre os diversificados projetos da sociedade civil e um estado que só gradualmente foi assumindo um lugar mais destacado, verificando-se muita resistência a que este fosse $o$ pivot institucional e/ou programático. Do Plano de Educação Popular (PEP) ao Instituto Português do Livro e da Leitura um longo caminho se percorreu, passando-se duma perspetiva mais instrumental, de endoutrinamento e formação técnica no trabalho, para uma perspetiva mais aberta, plural e formativa do cidadão integral. No horizonte estava a democracia cultural.

Sob a ditadura de Salazar e Caetano, a posição oficial centrou-se na imposição duma mundividência (e dum gosto oficial) de pendor ultranacionalista, católica conservadora e tendencialmente classista, onde cada indivíduo e grupo social deviam permanecer mais ou menos nas "origens", no ponto de partida social. Isso implicava pugnar por uma literatura nacionalista benquista, por uma oferta biblíaca controlada e instrumentalizada e pela vigilância, censura e repressão de tudo o que fosse indesejado, e que era praticamente tudo o resto. Num contexto de pressão democratizante, descolonizadora e de liberalização económica, a ditadura avança medidas mais qualificadoras e impregnantes do setor cultural, como o PEP e o Plano de Formação Social e Corporativa (PFSC), nos anos 1950, com impulso no cruzamento educação-cultura, na edição, nas bibliotecas, na encomenda e numa oferta livresca um pouco mais disseminada. Mas mesmo nestes planos o efeito era efémero (campanhas dalguns anos, sem continuidade) o foco era o endoutrinamento e a formação técnica para o trabalho, longe duma formação aberta e democrática. ${ }^{13}$

Perante esta situação, a sociedade civil teve a sua margem de manobra bastante limitada, fosse pelo receio de represálias, fosse pela falta de estímulo, de recursos ou de visão.

Neste quadro de constrangimentos, apenas a democracia podia reabilitar e pôr na ordem do dia os direitos culturais (Canclini, 2001; Lopes, 2007). Assim foi em Portugal após o derrube da ditadura, tanto do lado da sociedade civil como do estado.

Do lado do estado, foi a criação duma estrutura própria e integrada que permitiu consagrar esses direitos e dar resposta (em articulação com a sociedade civil) às expectativas e necessidades que circulavam na esfera pública. O debate sobre políticas culturais públicas começou então verdadeiramente. Discutiu-se tudo, até a necessidade dum ministério da Cultura. Quanto ao mundo do livro e da leitura, e em termos operacionais, em 1980 criou-se um organismo específico, o Instituto Português do Livro, ${ }^{14}$ cuja evolução se fez no sentido duma intervenção mais aberta, plural e formativa do cidadão integral. Foi aquando da sua reformulação em

13 Sobre esta evolução vd. Sampaio (1975-76) e Melo (2004).

14 Atualmente Direção-Geral do Livro, dos Arquivos e das Bibliotecas (desde 2007). Antes, tivera ainda as designações de Instituto da Biblioteca Nacional e do Livro (IBNL, 1992-97) e de Instituto Português do Livro e das Bibliotecas (IPLB, 1997-2007). 
Quadro 1 Principais apologistas portugueses do alargamento da leitura (século XX)

\begin{tabular}{|c|c|c|}
\hline Suporte de divulgação das ideias & Autor & Data \\
\hline $\begin{array}{l}\text { Opúsculos pioneiros de } 1900,1905,1914,1915 \text { e } 1919 \text {, este uma panorâmica sobre } \\
\text { As bibliotecas populares e móveis em Portugal }\end{array}$ & A. P. de Bettencourt Ataíde & $1900-19$ \\
\hline $\begin{array}{l}\text { Livro Os Arquivos e as Bibliotecas em Portugal (1920); profusa defesa da biblioteca } \\
\text { moderna em Anais das Bibliotecas e Arquivos (máx.1947-51) }\end{array}$ & António Ferrão & $1920-51$ \\
\hline $\begin{array}{l}\text { Artigos de 1924-52 no Arquivo Coimbrão e de } 1936 \text { na Seara Nova, estes depois } \\
\text { reunidos no livro seareiro Como Reformar as Bibliotecas Portuguesas, de } 1938\end{array}$ & José Pinto Loureiro & $1924-52$ \\
\hline $\begin{array}{l}\text { Conferências, artigos e livro sobre A cultura integral do indivíduo; projeto da col. } \\
\text { "Biblioteca Cosmos" (1941-48) }\end{array}$ & Bento de Jesus Caraça & $1931-48$ \\
\hline $\begin{array}{l}\text { Grupo não orgânico da revista de reflexão Seara Nova (Lisboa), destacando-se série } \\
\text { de artigos "Inquérito ao livro em Portugal", de Irene Lisboa (IL, 1943-45), reunidos em } \\
\text { livro seareiro homónimo }\end{array}$ & $\begin{array}{l}\text { J. Neto Soares, IL, Armando } \\
\text { Cortesão, A. Pedrosa, etc. }\end{array}$ & $1928-67$ \\
\hline $\begin{array}{l}\text { Associação de Classe dos Livreiros de Portugal/Assoc. de Classe dos Editores e } \\
\text { Livreiros de Portugal/GNEL/Assoc. Portuguesa de Editores e Livreiros: org. de feiras do } \\
\text { livro, de encontros e do boletim Livros de Portugal (1940-98) }\end{array}$ & AA.VV. & 1928- \\
\hline $\begin{array}{l}\text { Brochura e livro sobre o seu projeto de biblioteca móvel, 1945-47 e 1954; "Um inquérito } \\
\text { necessário" (Correio do Minho, 1955); livros As Bibliotecas, o Público e a Leitura (1956 } \\
\text { e 1983) e O Que É a "UNESCO" (1955); artigos na Vértice em 1955-60 }\end{array}$ & Victor de Sá (VS) & $1945-60$ \\
\hline $\begin{array}{l}\text { Livro Pequenas Bibliotecas. Como as Organizar Modernamente e como Utilizá-las (col. } \\
\text { "Biblioteca Cosmos", 1946); artigos sobre cultura e bibliotecas no Diário de Lisboa e na } \\
\text { Vértice (1949 e 1954); diretora da col. "Cosmos Juvenil" (anos 1960) }\end{array}$ & Ema Quintas Alves (EQA) & $1946-60$ \\
\hline $\begin{array}{l}\text { "Relatório do conservador do Museu-Biblioteca do Conde de Castro Guimarães" } \\
\text { (Boletim do M-BCCG, 1943); artigos sobre a oferta de leitura enquanto serviço público } \\
\text { básico segundo a UNESCO e exemplo luso da biblioteca itinerante municipal de } \\
\text { Cascais (jornais Ler, Diário de Lisboa e Diário Popular, 1953); projeto SBIF-FCG }\end{array}$ & Branquinho da Fonseca & $1943-74$ \\
\hline Grupo não orgânico da revista de reflexão e crítica Vértice (Coimbra e Lisboa) & $\begin{array}{c}\text { Armando Bacelar, A. Nogueira } \\
\text { Santos, EQA, VS, etc. }\end{array}$ & 1946- \\
\hline 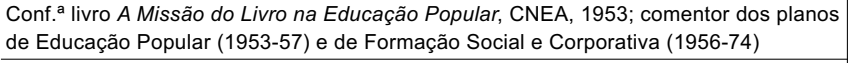 & Henrique Veiga de Macedo & $1953-61$ \\
\hline $\begin{array}{l}\text { Série de artigos "O povo tem fome de cultura" (O Estado de S. Paulo, 21/8/1955; } \\
\text { Notícias, 23/8/1955; O Primeiro de Janeiro, } 12 \text { e 29/10/1955; e Semana Portuguesa, S. } \\
\text { Paulo, 29/10/1955) }\end{array}$ & Jaime Cortesão & 1955 \\
\hline $\begin{array}{l}\text { Grupo da revista Cadernos BAD (1963-); encontros de bibliotecários e arquivistas } \\
\text { portugueses (1965-); APBAD- Associação Portuguesa de Bibliotecários Arquivistas e } \\
\text { Documentalistas (1973-) }\end{array}$ & AA.VV. & 1963- \\
\hline $\begin{array}{l}\text { Coautor do manifesto A Leitura Pública em Portugal (1983); v.g., recolha no livro Da } \\
\text { Biblioteca ao Leitor (Autores de Braga, 1996) }\end{array}$ & Henrique Barreto Nunes & 1983- \\
\hline $\begin{array}{l}\text { V.g. "A política do livro e da leitura na óptica do IPL" (Boletim Cultural, vol. } 6, \mathrm{n}^{\circ}{ }^{2} \text {, } \\
\text { 1984) e Os Livros e as Leituras. Novas Ecologias da Informação (2000), presidente do } \\
\text { IPLL (1987-91) }\end{array}$ & José Afonso Furtado & $1984-$ \\
\hline $\begin{array}{l}\text { Responsável, enquanto secretária de estado da Cultura (1985-90), pelo estudo e } \\
\text { lançamento da rede de bibliotecas públicas em Portugal, atual administradora da FCG } \\
\text { (desde 2004) }\end{array}$ & Teresa Gouveia & 1985- \\
\hline $\begin{array}{l}\text { Diretora do Serviço de Bibliotecas do IPLB (1987-2006), tendo elaborado relatórios } \\
\text { sobre as bibliotecas públicas em Portugal (1986-87 e 1996) e dinamizado o Programa } \\
\text { da Rede Nacional de Bibliotecas Públicas; } v d \text {. também Moura (2003) }\end{array}$ & Maria José Moura & 1986- \\
\hline $\begin{array}{l}\text { Coautora de relatório sobre as bibliotecas públicas em Portugal (1986); quadro do IPL/IPLL } \\
\text { e vice-presidente do IBNL (1992-96); comentora e coordenadora nacional da Rede de } \\
\text { Bibliotecas Escolares (1996-2014); comissária do Plano Nacional de Leitura desde } 2017\end{array}$ & Teresa Calçada & 1986- \\
\hline $\begin{array}{l}\text { Coautora de relatório sobre as bibliotecas públicas em Portugal (1986); comissária do } \\
\text { Plano Nacional de Leitura (2006-10); ministra da Educação (2009-11) e com tese de } \\
\text { doutoramento específica em Alçada (2016) }\end{array}$ & $\begin{array}{c}\text { Isabel Alçada / Isabel Veiga } \\
\text { / Isabel Vilar }\end{array}$ & 1986- \\
\hline $\begin{array}{l}\text { Ministro da Cultura (1995-2000); "O livro e a leitura - uma dimensão estruturante" } \\
\text { (em Hipóteses de Cultura, Editorial Presença, 1999) }\end{array}$ & Manuel Maria Carrilho & $1995-2000$ \\
\hline
\end{tabular}

Fonte: pesquisa na bibliografia ativa dos autores elencados e noutra informação disponível na internet. 
Instituto Português do Livro e da Leitura (IPLL), em 1987, que se lançaram os alicerces duma política sustentada na área: articulação entre políticas do livro e da leitura, rede pública de bibliotecas, apoio à edição e aos autores (subsídio à edição, viagens, financiamento de prémios literários), ${ }^{15}$ à internacionalização, mecenato, legislação para depósito legal e preço fixo do livro. ${ }^{16}$

Do lado da sociedade civil reforçou-se o associativismo existente (cooperativas culturais, coletividades socioculturais e educativas) e surgiram novos segmentos, alguns com um escopo abrangente e/ou comunitário (v.g., organizações de moradores, de desenvolvimento local), outros especializados (alfabetização, animação cultural, património e artes, socioprofissionais, etc.). Os sindicatos, partidos e outros grupos políticos ou militares também contribuíram para o desenvolvimento cultural, por vezes de modo conflituante (v.g. Dionísio, 1993; Neves, 2010: 195-207 e 353-367).

\section{Debates sobre o papel da leitura: entre informação, formação e recreação}

Importa também analisar os intensos debates sobre o papel da leitura, entre informação, formação e recreação, e que tipo de posição adotaram vários agentes: governantes, jornalistas e críticos literários, bibliotecários, associações representativas do mundo do livro, entre outros.

Foi persistente a crítica, vigilância, perseguição e repressão do que se considerava má leitura, que era frequentemente associada à literatura de ficção, e à leitura mais recreativa. Era uma postura com largo respaldo: no Index do Vaticano e na vigilância das leituras pelas igrejas católicas; nas censuras social e oficial. ${ }^{17}$ Mas também em notas prescritivas emanadas do Serviço de Bibliotecas Itinerantes e Fixas da Gulbenkian, que enunciavam os livros das várias ciências ("aplicadas" "puras", "sociais" e humanas - filosofia, filologia e história) como tendo "maior qualidade" do que "a literatura". 18

O olhar oficial não se quedava na censura administrativa às publicações, enquadrou também a leitura concedida nas bibliotecas estatais, com o seu principal diploma (decreto n. 19.952, de 1931) ditando proibições de leituras para certos

15 São 13, pelo menos, os prémios que foram sendo cofinanciados por esta estrutura setorial, designadamente o prémio Camões e os da APE, APBAD, Pen Clube Português, Fundação Casa de Mateus, Sociedade de Língua Portuguesa e Associação Internacional de Críticos Literários.

16 Sobre estes temas vd. Santos (1998), Santos, Gomes e Neves (2000), Lopes (2004 e 2007), Melo (2004), Gomes, Farinha e Martins (2011) e Neves (2012).

17 Partindo de Barthes e Compagnon, Furtado (2000: 226-227) fala da condenação, no mundo ocidental, do modelo de leitura como fruição e divertimento por parte da Igreja e da Escola republicana. Sob o salazarismo, desconhece-se intervenção condenatória pelos sobreviventes desta última, i.e., dos centros escolares republicanos e afins. Ademais, muitos republicanos persistiram na apologia duma cultura humanista. A qual favorecia uma perspetiva abrangente, como preconizou Santos (1949: 111), elogiando os princípios específicos enunciados pela UNESCO em 1948 e plasmados no manifesto de 1949.

18 Cit. Anónimo (1972: 14); para mais detalhes $v d$. Melo (2004). 
públicos: "Tanto na Biblioteca Popular Central de Lisboa, como em todas as bibliotecas populares e móveis, é absolutamente vedado fornecer livros, revistas e panfletos que contenham ofensas à moral e às religiões, ou doutrinas contrárias à segurança do Estado".

No quadro católico, foi comum a combinação entre vigilância da narrativa de ficção e da literatura para a juventude. Um dos seus mais prolíficos zeladores foi Zacarias de Oliveira, que desdobrou os seus alertas pela Rádio Renascença, imprensa e livro. Por volta de 1955, inquiriu os jovens portugueses sobre as suas leituras, e concluiu que o romance imperava, o que era extensivo à sociedade e motivo de desqualificação: “Se todos são atraídos por esta espécie de leitura, que não exige esforço de atenção, nem de pensamento, a juventude sente-se arrastada por ela" (cit. em Melo, 2004: 217). Seguia-se a procura de livros de viagens e de biografias, considerados por Oliveira afins do anterior, o que revelava outro preconceito (ibidem).

A literatura infantil e juvenil mereceu uma especial atenção dos salazaristas, mais de modo negativo do que positivo. Desde logo, o estudo da literatura infantil apenas entrou nas escolas do Magistério Primário após a queda da ditadura. ${ }^{19}$ Depois, neste âmbito podia articular-se formação e recreação, mas a formação prevaleceria e seria nacionalista e cristã. Para o efeito foi criado em 1950 um organismo censório específico, a Comissão Especial para a Literatura Infantil e Juvenil / Comissão de Literatura e Espectáculos para Menores (vd. Coutinho, 2015). Esta não se limitou a censurar a produção literária específica - impôs uma nacionalização do olhar na feitura (e tradução/adaptação) desse tipo de literatura; aconselhou omitir-se alusões à inveja social, o incentivo ao confronto social ou às preocupações de adultos. ${ }^{20} \mathrm{O}$ espírito de missão ao serviço do catolicismo é central em figuras deste organismo, como João Serras e Silva ${ }^{21}$ e o Pe. Moreira das Neves, tendo este último sido uma figura influente junto do cardeal Cerejeira e com postos de direção na imprensa e na rádio católicas. Também o deputado Manuel Marques Teixeira se insurgiu na Assembleia Nacional, em 1950, contra aquelas obras que constituíam "hediondos veículos de expansionismo de ideias estranhas e corruptoras, atrofiando o caráter, abalando os bons costumes, amortecendo o que deve continuar a ser peculiar à sensibilidade da nossa gente". ${ }^{22}$

Sob a ditadura foram poucos os que tentaram romper com este estigma, provindo as exceções sobretudo dos apologistas das bibliotecas para todos. Assim, Branquinho da Fonseca advertia em 1953:

As bibliotecas [de "leitura corrente"] deviam ser organizadas correspondendo a todos os interesses do público: ser de diversão e de cultura. E ter até os maus romances, maus no bom sentido. Sei até de leitores que vieram um dia à biblioteca procurar um livro inferior e que ficaram admirados e entusiasmados ao verificarem que havia outros

19 Rocha (1992: 87). Posteriormente, também integrou os programas das escolas superiores de educação dos institutos politécnicos (Gomes, 1999: 88).

Respetivamente, Melo (2016: 484) e Magalhães (2008: 161-162).

Vd., v.g., http://www.sardoalmemoria.net/home/sardoalenses-ilustres/doutor-joao-serras-e-silva Diário das Sessões, n. ${ }^{\circ}$ 62, 14/12/1950, p. 155. 
melhores. [...] A leitura é um hábito. É preciso despertá-lo e depois mantê-lo. E orientá-lo. Porém com aquele tato de quem oferece e não com o chicote de quem obriga. Por isso, insisto, a secção infantil é da maior importância. [...] Muitos dos atuais leitores da biblioteca de Cascais começaram por vir ler histórias da Carochinha [...] e agora vêm folhear todas as histórias do Arco-da-Velha, das nações e dos homens, ler todas as filosofias e filosofantes, refrescar os olhos em todas as imagens da arte antiga e moderna. ${ }^{23}$

\section{E aditava:}

Falta o problema financeiro. Mas, quanto a este, pergunto e peço desculpa pela ousadia: dum orçamento que há um quarto de século tem saldo, não poderá tirar-se uma verbazinha para uma coisa que há séculos tem deficit - a cultura e a educação nacionais? (Fonseca, 1954).

Sabemos a resposta: teve que ser a Fundação Gulbenkian a abrir a bolsa e, depois, o estado democrático.

Em breve seria a vez de a FCG ser criticada, por alegadamente fornecer uma oferta também ela restrita, elitista (via exemplos extraídos do órgão Boletim Informativo), muito ligada aos escritores da casa e tentando impor uma orientação de gosto. Tais críticas afloram, por exemplo, na revista Crítica, animada por Eduarda Dionísio e Jorge Silva Melo em 1971/72. ${ }^{24}$ Após copiosos exemplos, a Crítica conclui:

Faculta-se efetivamente o acesso material ao livro, o que é bom. Mas a que livros? (Seria interessante poder-se analisar a constituição das bibliotecas). Facultar-se-á o acesso a uma cultura? Parece que não se tratará[,] de qualquer forma[,] de uma cultura atual e viva. Não se tratará nunca por estes processos de um acesso ativo, livre e crítico (Anónimo, 1972: 15).

Em obra de Tengarrinha (1973) denunciou-se ainda a quase ausência de livros de José Cardoso Pires nas bibliotecas da FCG. Após o derrube da ditadura, a pressão das populações e dos encarregados de bibliotecas da FCG levou à rápida incorporação de temas (e autores) antes ocultados por força da censura e dum certo conservadorismo na orientação dos serviços (Melo, 2004). A pressão abarcou ainda a democratização cultural e a própria gestão da FCG, integrando-se na contestação genérica feita pelos restantes funcionários da casa. Refere um comunicado de 10/3/1975 da respetiva Comissão Executiva dos Trabalhadores que estes pretendiam que a sua instituição deixasse de estar "divorciada do país real" e de manter "barreiras entre criadores e utilizadores, entre produção e consumo, entre elites e massas" (cit. em [Gomes], 2005b). Acusava ainda a administração vigente de prosseguir a mesma "política cultural inegavelmente classista do passado". ${ }^{25}$ Também

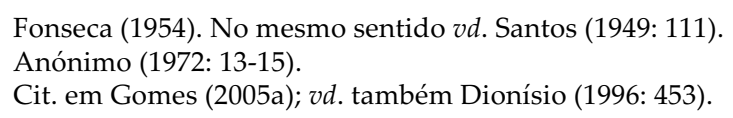


um estudo feito à oferta bibliográfica da FCG permitiu detetar algumas lacunas relevantes (Melo, 2004).

Sobre a leitura no Portugal de 1970/71, a revista Crítica notava que ela estava então mais equilibrada, com o romance a ser lido como romance e não "para confirmar uma tese (sociológica, psicológica)" ou "para obter informações", função doravante entregue ao ensaio, mais diversificado, atual e próximo das expectativas do leitor, mas então também mais na moda, o que podia "vir a ser um mal" ${ }^{26}$

O legado censório e prescritivo para a literatura infanto-juvenil em Portugal deixou marcas. A nível oficial, foi mitigado contemplando núcleos próprios nas abrangentes seleções bibliográficas para as bibliotecas municipais (e segundo normas internacionais). Mas a controvérsia prosseguiu quanto ao cânone literário, levando a tomadas de posição radicais, como a de Ana Maria Magalhães, que, numa proposta bibliográfica para o IPLB, "optou por apresentar, não uma seleção, mas todas as obras publicadas pela primeira vez em Portugal entre 1999 e abril de 2001".27

Os estudos sobre os hábitos de leitura, incrementados a partir dos anos 1980, alimentaram o debate sobre o lugar social e cultural da leitura, embora visassem outros fins (por serem estudos de mercado, encomendas oficiais de inquéritos, etc.). Involuntariamente, potenciaram o lugar-comum de que em Portugal se lê muito pouco (uma prática minoritária, portanto), a partir do dado reincidente nos inquéritos de piores resultados na leitura de livros durante o ano anterior face à maioria dos seus homólogos para outros países. Porém, vários estudiosos matizaram este indicador ponderando o atraso na alfabetização e na escolarização, o ónus duma ditadura prolongada, e chamando a atenção para outras modalidades de leitura (da leitura de periódicos à leitura na internet) e a relevância das competências na literacia digital para a capacidade de processamento da informação e de compreensão crítica do mundo (Melo, 2004; Santos et al., 2007; Alçada, 2016). Ademais, dados sobre a evolução recente das práticas de leitura indicam que houve um recuo dos não leitores (de 12\% em inquérito de 1995 para 5\% em análogo de 2006/7), um aumento dos leitores (de jornais, revistas e livros) e uma maioria (dos inquiridos) a crer numa evolução positiva nos últimos dez anos, embora os "pessimistas" tenham um peso significativo, em especial junto dos mais jovens e dos leitores cumulativos (estes sendo os que leem nos três suportes atrás referidos; $v d$. Santos et al., 2007: 173-174 e 182).

\section{Outros debates ligados à maior riqueza de opções}

Houve também debates mais circunscritos que tiveram relevância, ao favorecerem (ou salvaguardarem, consoante os pontos de vista) uma maior riqueza de opções (do lado da oferta, da distribuição e da procura), casos das discussões sobre "a crise do livro", a projeção do livro português e da leitura, o prémio Nobel da Literatura,

26 Anónimo (1971:14-15, cits. 15). A importância do ensaio foi corroborada por vários estudos posteriores: v.g. Dionísio (1993), Melo (2004), Medeiros (2010), Silva (2013, este para o ensaio político). 
o preço fixo do livro e a "morte do livro". Deixo de lado, por limitações de espaço, as questões da propriedade literária (ou direitos de autor) e da conexa remuneração e penalização pela cópia privada, porque mais circunscritas, bem como questões mais de índole profissional.

O debate sobre a "crise do livro", ou "crise do livro português", foi cíclico, recorrente e ligado a diversas questões. ${ }^{28}$ Aquilino Ribeiro, presidente da Sociedade Portuguesa de Escritores (1956) e sócio efetivo da Academia de Ciências de Lisboa (1957), conectou-a em 1957 à dificuldade da profissionalização do escritor (um problema estrutural) e de exercício da crítica no país (mitigada pela existência da censura oficial). Ligou-a ainda ao ocaso da literatura face a outras modalidades da cultura de massas. ${ }^{29}$ A decadência ou enfraquecimento do livro (e da literatura) associado à concorrência doutros media será um debate do espaço ocidental e que reaparece em Portugal no final do século. Aqui houve quem falasse numa transformação estrutural, "a mudança de um sistema cultural assente no livro e no cânone para um sistema aberto, pluricultural e plurideológico como é o da segunda metade do séc. XX", com a alteração de comportamentos induzida em boa medida pela televisão (Ribeiro, 1997).

Em simpósio de 1992, sobre "Cultura e indústria da cultura", Orlando Vitorino e outros oradores colocaram a causa na uniformidade provocada pela indústria cultural de massas, na "industrialização da cultura". ${ }^{30}$

O debate polarizou-se: houve quem criticasse esta tendência, e a ação da televisão em particular, que favorece a passividade acrítica do cidadão e restringe sobremaneira o tempo para outros consumos culturais mais edificantes; mas houve igualmente quem achasse, como a pedagoga Maria Emília Brederode Santos, que a televisão pode ser um meio educativo, se bem orientada, ajudando na iniciação à leitura com programas como "Rua Sésamo" (1989-97). ${ }^{31}$

Este é, também ele, um debate generalizado ao mundo ocidental, com o teórico Michel Peroni sintetizando as posições entre discursos teléfilo e teléfobo, um sustentando que a televisão fomenta a leitura e o outro o oposto (apud Furtado, 2000: 238). A posição da pedagoga supracitada - que parece ecoar a perspetiva construtiva de Umberto Eco na famosa obra Apocalípticos e Integrados (vd. Furtado, 2000: 239-248) - supera aquela dicotomia e leva o debate para outro patamar, o da exigência de critérios de qualidade na programação, e da articulação (ou não) desse critério com as necessidades de audiência, nas televisões pública e privada. Ademais, são vários os exemplos de livros vendidos à boleia da sua transposição para o cinema (v.g., Guedes, 2001: 208) ou para séries de televisão.

Estes posicionamentos podem ser vistos como não opostos, no sentido em que a evolução sociocultural em Portugal levou a que não houvesse uma consolidação da fase da alfabetização generalizada sem televisão (devido ao lento decréscimo do analfabetismo), ocorrendo uma passagem mais rápida da iliteracia para o acesso de

\footnotetext{
Sobre o tema vd., entre outros, Pereira (1972), Melo (2004: 208-216), e Medeiros (2010). A saber: rádio, cinema, televisão, futebol e carro (Valdemar, 2015).

AA.VV. (1992: 43).

AA.VV. (1992) e Conselho Nacional de Educação (CNE, 1995) (o texto da mencionada pedagoga está inserto em idem: 23-32).
} 
massas à televisão e prejudicando a consolidação dos hábitos de leitura do livro (e da sua intensidade junto dos leitores mais ledores) e do impresso em geral, bem como duma maior diversificação dos consumos culturais. ${ }^{32}$ Esta singularidade portuguesa teve como efeito que: "Com e por causa do salazarismo, o pós-modernismo surge, em Portugal, no prolongamento da pré-modernidade" (Rebelo, 1998: 346).

Neste quadro de crise do livro, uma questão relevante remete para a projeção do livro e do autor portugueses além-fronteiras, o que foi dificultado sob o Estado Novo, sobretudo devido à fraca presença de editores lusos nas principais feiras internacionais, ao fraco apoio à sua expansão em países estratégicos (como o Brasil) e à sua tradução (v.g. Anónimo, 1966: 43). Não havia ainda "a exportação regular e institucionalizada do livro português", como lamentava o Grémio Nacional dos Editores e Livreiros (GNEL) no tardio ano de 1973 (GNEL, 1973). Também foi tida como "imprescindível" a existência dum "repertório anual de livros portugueses disponíveis" (idem), que só surgiria em 1985, via catálogo Livros Disponíveis da APEL (cf. Beja, 2012: 119).

Seja como for, e em contramão, as organizações representativas do setor do livro e das bibliotecas legaram contributos a ter em conta.

Desde logo, importa regressar ao legado das organizações representativas dos bibliotecários, o grupo da revista Cadernos BAD (1963-) e a APBAD (1973-), que desde os anos 1960 batalharam em prol da biblioteca para todos e pela existência duma rede nacional de bibliotecas públicas de âmbito local. ${ }^{33}$ Foram elas a vanguarda e a grande força dinamizadora neste domínio, juntamente com alguma imprensa e opinião pública, com algum associativismo e o exemplo das bibliotecas itinerantes e fixas da FCG ( $v d$. quadro 1). Além do fomento da leitura, essa e outras redes (como a escolar) permitiram assegurar grandes encomendas aos editores.

O GNEL batalhou muito tempo por mais apoios estatais, pelo embaratecimento dos custos de produção, distribuição (sobretudo para o mercado colonial) e exportação, e pela difusão do livro enquanto bem cultural e educativo. A sua ação foi criticada no que respeita ao encarecimento desproporcionado do livro estrangeiro através do câmbio livreiro, o que prejudicaria sobretudo o livro mais barato e o livro brasileiro. ${ }^{34}$ A sua sucessora APEL bateu-se sobretudo por maiores apoios financeiros do estado, depois de asseguradas por este aquelas grandes encomendas de livros, os apoios para presenças em feiras do livro importantes (como a de Frankfurt) e os acordos para a regulação da edição (via criação do ISBN e do ISSN para Portugal e da lei do preço fixo do livro). A entrada da APEL na Feira de Frankfurt muito ajudou a promover o livro e os escritores portugueses; neste particular, 1997 foi um marco, havendo quem diga que a escolha de Portugal como país convidado nesse ano contribuiu para a atribuição do prémio Nobel a José Saramago, no ano seguinte. ${ }^{35}$

Sobre o tema vd. também Maria de Lourdes Lima dos Santos (em CNE, 1995: 50-57) e Coelho (2004).

Para um historial deste movimento vd. Cadernos BAD, n.os 1 e 2 de 2012/2013.

Cf. posição do jornal Crítica no seu n.․ 4 (1972), pp. 1 e 14-15. Sobre a APEL vd. Guedes (2001) e Beja (2012).

35 A afirmação é de Rui Beja (2012: 84). Também Maria do Rosário Pedreira refere 1997 como ano de explosão para as traduções de livros em língua portuguesa no planeta e até 2000 (vd. Perfeito, 2015). 
Este prémio Nobel da Literatura foi também muito comentado e suscitou variados debates, dos quais destaco três. Em primeiro lugar, o prémio enquanto galardão fundamental para afirmar a literatura de língua portuguesa no mundo e os escritores portugueses (era corrente dizer-se que as letras lusitanas não tinham visibilidade na atualidade por falta dum prémio destes). ${ }^{36}$ Em segundo lugar, acentuou-se que havia escritores portugueses com projeção e muito lidos, com fama extramuros mas também intramuros, realçando-se que Saramago era um best-seller no país e que havia filas imensas para as inúmeras sessões de autógrafos nas feiras do livro às quais tinha gosto em comparecer e de modo regular. Antes disso, era corrente dizer-se que tínhamos deixado de ter escritores (apenas tínhamos poetas), ou que não éramos um país de romancistas, e que não se lia em Portugal. Como lamentava Ana de Castro Osório já em 1928: “Desde que desapareceram da vida Júlio Denis, Camilo Castelo Branco e Eça de Queirós, e os realistas, foi decretado pela crítica que não havia mais romancistas em Portugal, e realmente nesta sugestão os escritores retraíram-se e procuraram outros rumos, e o público ficou na convicção de que a veia novelista deixara de existir em Portugal" (Osório, 1928: 32). Décadas volvidas, um destacado crítico literário reformulava (e assumia parcialmente) esta perspetiva, dizendo "ter entrado em crise a novelística, florescente na segunda metade do século XIX e na primeira do XX, quer dentro, quer fora das nossas fronteiras" (Simões, 1973). Sempre a questão da literatura hodierna. Em terceiro e último lugar, atualizou o debate sobre a censura no Portugal contemporâneo, ajustando-se contas com a perseguição oficial movida a Saramago, em 1992, com o veto da Secretaria de Estado da Cultura à candidatura do seu livro Evangelho segundo Jesus Cristo (1991) ao prémio Europeu de Literatura Aristeion (da Comissão Europeia), por "atentar contra a moral cristã" e após supostas pressões anti-blasfemadoras da Igreja católica. ${ }^{37}$ Não sem esquecer a suposta retaliação que Saramago exercera, por motivos político-ideológicos, sobre jornalistas do Diário de Notícias, quando fora seu diretor-adjunto, no período revolucionário de 1974/75.

O generoso financiamento indireto e direto da edição pelo estado (via livro escolar, compras das bibliotecas estatais, programas de subsídio à edição do IPLL/IBNL/IPLB, Fundação para a Ciência e a Tecnologia, etc.) acabou por esvaziar o debate, pelo lado dos editores e livreiros, quanto às políticas de médio e de longo prazo e ao lugar da edição de Portugal no mundo.

A lei do preço fixo do livro, vigente desde 1996, merece destaque, desde logo pelo seu alcance económico, viabilizando a existência dum maior contingente de livrarias e editoras, já que dificultou o esmagamento da concorrência por via de fortes promoções da parte de grandes grupos. Associou-se a um debate político não só sobre política da edição como também sobre política cultural em geral, em torno da questão do alargamento do acesso ao livro e da diversidade (e pluralidade) do mundo do livro

36 Sobre esta questão $v d$. observação lapidar de especialista galego em literatura (Freixanes, 1999: 141).

37 Cf.https://pt.wikipedia.org/wiki/O_Evangelho_segundo_Jesus_Cristo\#cite_note-8.Ogoverno acabou por repor o livro na sua lista, após “aceso debate sobre a cultura em Portugal”, com Saramago então a pedir ao júri para não o incluir (Pereira e Almeida, 1998: 5). 
e da edição. ${ }^{38}$ Com efeito, muito embora os detratores da medida tenham procurado argumentar contra um eventual encarecimento do livro (ou não descida do seu preço de venda) e uma eventual penalização de potenciais leitores com menor poder de compra, ${ }^{39}$ o certo é que a salvaguarda da diversidade (e pluralidade) do mundo do livro e da edição, do lado da oferta, era (e é) uma questão candente, ressoando no debate que então existiu no país e que está implícito em debates internacionais que prosseguem, em várias estruturas em que Portugal está integrado, da União Europeia à Ibero-América. Esses debates dizem respeito justamente à salvaguarda da diversidade cultural e atravessaram vários fóruns públicos, desde os media à UNESCO e cimeiras ibero-americanas..$^{40} \mathrm{~A}$ título ilustrativo, o relatório "A nossa diversidade criadora" (da Comissão Mundial da Cultura e do Desenvolvimento, de 1996) constatou "um muito nítido antagonismo entre os interesses comerciais e os interesses públicos", preconizando o fomento da leitura como um fim de longo prazo e o desenvolvimento da indústria nacional da edição, este para combater a distribuição muito desigual da produção de livros (cf. Martins, 1999: 148-149).

Outro debate interessante foi o da "morte do livro", sentenciada por McLuhan e em parte relacionada com a questão anterior, mas que dela se distingue..$^{41}$ Trata-se dum debate internacional que discute se a gradual disseminação do digital levará ou não ao fim do livro-objecto físico (livro impresso) tal como o conhecemos atualmente. Em Portugal, este debate envolveu sobretudo três tipos de agentes: os especialistas das ciências da informação e comunicação, algum jornalismo especializado, e sociólogos da cultura e informação. Um dos principais teóricos animadores tem sido José Afonso Furtado.42

Segundo este autor, "a expansão das Novas Tecnologias de Informação e Comunicação", mormente da internet, levou à "emergência de formas que desafiam e suplementam o livro impresso e a literacia tipográfica" (Ribeiro, 2007: 10). Estamos perante a hipótese duma transformação civilizacional relevante, pelo que importa ter presente o quadro histórico apropriado. Assim, Chartier (2002) insere a sua perspetiva numa visão de longa duração da história do livro e dos meios de comunicação, e vê a transmissão de textos por via electrónica iniciada em meados do século XX enquanto nova revolução a juntar às anteriores, que surgiram com a leitura silenciosa dos séculos XII-XIII e a explosão de formatos impressos e novos leitores no século XIX. A afirmação do digital é tida como um fenómeno radicalmente novo:

38 V.g., Carrilho (1999: 114-115 e 168-169), Santos, Gomes e Neves (2000), Gomes, Farinha e Martins (2011) e Beja (2012: 93-99). Este diploma foi influenciado sobretudo pelos seus congéneres espanhol, de 1975, e francês, de 1981 (Lei Lang; $v d$. Rouet, 2007 [2000]). O senão foi a paralela introdução do IVA no livro, e para um valor significativo. Seria, porém, mitigada com a dedução na matéria coletável do IRS de despesas de consumo de bens e serviços culturais.

39 Houve ainda os argumentos da livre concorrência e da não intervenção estatal: para o debate em Portugal vd. Pina (1993), Sepúlveda (1993) e Santos, Gomes e Neves (2000).

40 Este relatório da ONU inspirou a Declaração Universal sobre a Diversidade Cultural, de 2001 (Maraña, 2010: 11).

41 Este debate vem de trás, do século XIX, como explanam Rouet (2007 [2000]) e Eisenstein (2011).

42 V.g., Furtado (2000: 225-256 e 424-435) e Ribeiro (2007). 
abrange, pela primeira vez em simultâneo, um conjunto de mutações que até agora tinham ocorrido em separado. Na verdade, muitas das categorias através das quais nos temos relacionado com a cultura escrita estão a alterar-se, pois a revolução do texto eletrônico é, ao mesmo tempo, uma revolução [ou ruptura radical] na técnica de produção e de reprodução dos textos, uma revolução no suporte da escrita e uma revolução nas práticas de leitura. ${ }^{43}$

Para outros, as mudanças não são revolucionárias, são evolutivas, daí que "tanto os indivíduos como as organizações acabarão por incorporar as tecnologias de rede nas suas práticas como incorporaram outros media e tecnologias anteriores" (Ribeiro, 2007). Pode resultar numa mudança de paradigma, mas não implica a remoção dos media anteriores, apenas a reconfiguração do seu posicionamento no interior do sistema mediático. Ou seja, há uma via alternativa para o confronto linear "tecnófilos" vs. "tecnófobos". Os dados empíricos, incluindo os do âmbito português (v.g. Santos et al., 2007, e Alçada, 2016), comprovam a tendência para a sobreposição (e complementaridade, para certos autores) entre "velhos" e "novos" suportes e tecnologias de comunicação, mas não esvaziam o debate mais qualitativo e de maior alcance sobre o peso de cada qual na formação pessoal e no estímulo do espírito crítico.

A expansão do digital originou também debates mais transversais, articulando comunicação, educação e cultura numa perspetiva inclusiva e de futuro. Dele emergiu um Livro Verde para a Sociedade da Informação, aberto à discussão pública em 1996/7 e contendo 72 medidas (cf. Granado, 1997). Do alerta para a necessidade de assegurar a literacia digital a toda a população passou-se paulatinamente para a necessidade de assegurar uma plena capacidade de leitura nos vários suportes e tecnologias de comunicação, nos modos e intensidades de leitura, de modo a não comprometer o futuro das sociedades em apreço, com estudiosos, organizações, recomendações (v.g., UNESCO e OCDE) e programas (v.g., PNL e seus equivalentes extramuros) ligados à educação, a conceber a leitura como uma competência-chave decisiva para todos (Alçada, 2016).

\section{Breves notas finais}

Referiu recentemente o ensaísta Gabriel Zaid: "A leitura de livros cresce aritmeticamente; a escrita de livros cresce exponencialmente" (2008: 29). Nunca se publicou tanto livro, e nunca tantos se sentiram com tanta falta de tempo para ler, e não só. E quanto ao debate sobre a leitura e o livro, também escasseou ou foi suficiente?

Quanto ao passado recente, o que se carreou para o caso português indica carência e fortes constrangimentos do debate (e da ação) cultural no longo período ditatorial, com múltiplas causas, desde causas culturais (ligadas a paradigmas culturais e civilizacionais bloqueadores) a causas políticas (outras prioridades oficiais, perfil antidemocrático, censura política, etc.) e sociais (v.g., resistência à

43 Furtado dixit, em entrevista a/em Ribeiro (2007). 
escolarização ou à massificação do ensino). Os efeitos foram duradoiros, em especial: atrasos e anomalias estruturais na literacia da população; atrasos e bloqueios na expansão do livro e da leitura; défices de articulação entre educação e cultura, entre políticas do livro e da leitura; dificuldade das instituições públicas e da sociedade civil em fomentarem o empoderamento e a emancipação dos cidadãos e das comunidades; e, por fim, carência de informação e de discussão aberta. Verificaram-se estas constantes e características históricas a partir da análise do que elegemos como os principais temas de debate cultural para a área do livro e da leitura. Não obstante, ainda que limitado e condicionado, o debate cultural que se fez intramuros envolveu algumas das mais conceituadas e/ou dinâmicas individualidades e grupos culturais do país (durante a ditadura quase todos desafetos ao poder ou mesmo ligados à resistência cultural), ecoou tendências, argumentos e reflexões vindos do exterior, e deu um contributo relevante para a democratização da própria sociedade.

Quanto ao presente, a resposta caberá aos estudiosos do século XXI, mas importa notar que a nova era se enquadra já num contexto histórico-institucional em que diversas organizações públicas desenvolveram expressivo trabalho de planeamento, estudo e monitorização.

\section{Referências bibliográficas}

AA.VV. (1992), Cultura e Indústria da Cultura, Faro, FCG e Câmara Municipal de Faro. Alçada, Isabel (2016), O Plano Nacional de Leitura. Fundamentos e Resultados, Alfragide, Caminho.

Anónimo (1966), “O livro - temas actuais", Espiral - Cadernos de Cultura, 13, pp. 42-47.

Anónimo (1971), “Que lemos hoje?”, Crítica, 1, pp. 1 e 14-15.

Anónimo (1972), “Uma cultura popular?”, Crítica, 6, pp. 13-15.

APCEP - Associação Portuguesa para a Cultura e Educação Permanente (2016),

"Portugal precisa de um novo impulso para a educação e formação de adultos", Jornal de Letras, 1181, suplemento JL/Educação.

Beja, Rui (2012), A Edição em Portugal, 1970-2010. Percursos e Perspetivas, Lisboa, APEL.

Bettega, Emilie (2008), Place et Rôle des Bibliothèques au Sein des Politiques Culturelles en France, en Espagne et en Italie, Villleurbane (Lyon), Ecole Nationale Supérieure des Sciences de l'Information et des Bibliothèques, diploma de conservador de biblioteca.

Canclini, Nestor Garcia (2001), “Definiciones en transición”, em D. Mato (org.), Estudios Latinoamericanos sobre Cultura y Transformaciones Sociales en Tiempos de Globalización, Buenos Aires, Clacso, pp. 57-67.

Candeias, António (2004), Alfabetização e Escola em Portugal nos Séculos XIX e XX, Lisboa, FCG.

Candeias, António (coord.) (2005), Modernidade, Educação e Estatísticas na Ibero-América dos Séculos XIX e XX, Lisboa, Educa.

Carrilho, Manuel Maria (1999), Hipóteses de Cultura, Lisboa, Editorial Presença.

Chartier, Roger (2002), “Before and after Gutenberg: a conversation with Roger Chartier", em The Book and the Computer. Book Culture at the Crossroads, Online Symposium, evento realizado na internet a 30 de abril. 
CNE - Conselho Nacional de Educação (1995), O Livro e a Leitura. O Processo Educativo. Actas do Seminário Realizado em 6 de Junho de 1994, Lisboa, CNE.

Coelho, Eduardo Prado (2004), Crónicas no Fio do Horizonte, Porto, Asa.

Costa, António Firmino da (1997), "Políticas culturais: conceitos e perspectivas", OBS, 2, pp. 10-14.

Costa, António Firmino da, et al. (2010), Avaliação do Programa Rede de Bibliotecas Escolares, Lisboa, Ministério da Educação.

Coutinho, António Martinó de Azevedo (2015), “Camaradagens", Largo dos Correios (blogue), 7 de janeiro a 20 de fevereiro, (posts 01-10).

Dionísio, Eduarda (1993), Títulos, Acções, Obrigações (a Cultura em Portugal, 1974-1994), Lisboa, Edições Salamandra.

Dionísio, Eduarda (1996), “As práticas culturais", em António Reis (coord.), Portugal, 20 Anos de Democracia, Lisboa, Temas \& Debates, pp. 443-489.

Eisenstein, Elizabeth L. (2011), Divine Art, Infernal Machine. The Reception of Printing in the West from First Impressions to the Sense of an Ending, Filadélfia, University of Pennsylvania Press.

Fernandes, Rogério (1993), “Marcos do processo histórico da alfabetização de adultos em Portugal", Colóquio Educação e Sociedade, 2, pp. 115-144.

Fonseca, Branquinho da (1954), "As bibliotecas e a necessidade da sua extensão", Diário de Lisboa, 26 de janeiro, p. 14.

Freixanes, Víctor (1999), “El buscador de perlas (sobre la identidad de la edición en España y su relación con Portugal)", em V. Freixanes, Las Fábricas de la Literatura, Oviedo, Universidad de Oviedo, pp. 133-147.

Furtado, José Afonso (2000), Os Livros e as Leituras. Novas Ecologias da Informação, Lisboa, Livros e Leituras.

GNEL - Grémio Nacional dos Editores e Livreiros (1973), Conclusões do I Encontro de Editores e Livreiros, Lisboa, GNEL.

Gomes, Adelino (2005a), "Gulbenkian e RTP em ebulição”, Público, 23 de março, p. 13, dossiê "Memória 30 anos de PREC".

Gomes, Adelino (2005b), “ELP e ainda a Gulbenkian”, Público, 24 de março, p. 14, dossiê "Memória 30 anos de PREC".

Gomes, José António (1999), “A literatura para crianças e jovens no pós-25 de Abril”, Vértice, 92 (2. érie), pp. 88-93.

Gomes, Rui Telmo, Cristina Farinha, e Sara Martins (2011), “Portugal / 1. Historical perspective: cultural policies and instruments", em Council of Europe (org.), Compendium of Cultural Policies and Trends in Europe, Estrasburgo, Council of Europe, disponível em: http://www.worldcp.org/portugal.php (última consulta em fevereiro de 2018).

Granado, António (1997), “O desafio mais importante”, Público, 23 de abril, p. 24.

Guedes, Fernando (2001), O Livro como Tema, Lisboa, Verbo.

IFLA - International Federation of Library Associations and Institutions (1988), Pautas para Bibliotecas Públicas Preparadas por la Sección de Bibliotecas Públicas de la FIAB, Madrid, Dirección General del Libro y Bibliotecas.

IFLA - International Federation of Library Associations and Institutions (2016), “IFLA/UNESCO Public Library Manifesto 1994", IFLA.org (sítio de internet). 
Lingelback, Gabriele (2011), "Intercultural transfer and comparative history", Traversea, 1, pp. 46-59.

Lopes, João Teixeira (2004), “Trinta anos de políticas culturais: a revolução inacabada e o país complexo", em F. Louçã e F. Rosas (orgs.), Ensaio Geral - Passado e Futuro do 25 de Abril, Lisboa, Publicações Dom Quixote, pp. 142-55.

Lopes, João Teixeira (2007), Da Democratização à Democracia Cultural. Uma Reflexão sobre Políticas Culturais e Espaço Público, Porto, Profedições.

Lourenço, Vanda (2010), “Cultura e educação: desafios de uma política partilhada”, em M. de L. L. dos Santos e J. M. Pais (orgs.), Novos Trilhos Culturais, Lisboa, Imprensa de Ciências Sociais, pp. 237-242.

Macedo, Henrique Veiga de (1953), A Missão do Livro na Educação Popular, Lisboa, CNEA. Magalhães, Ana Maria (2001), A Literatura Infanto-Juvenil na Viragem do Século, Lisboa, IPLB. Magalhães, Violante (2008), Sobressalto e Espanto, Lisboa, FLUL, tese de doutoramento. Maraña, Maider (2010), Culture and Development. Evolution and Prospects, UNESCO Etxea, working papers n. ${ }^{\mathrm{o}}$ 1, disponível em: http://www.unesco.or.kr/eng/front/programmes/ links/6_CultureandDevelopment.pdf (última consulta em fevereiro de 2018).

Martins, Jorge M. (1999), “O livro e a UNESCO: para uma visão integrada da cadeia do livro no quadro das novas tecnologias", Sociologia, Problemas e Práticas, 30, pp. 145-163, disponível em: http://sociologiapp.iscte-iul.pt/pdfs/10/116.pdf (última consulta em fevereiro de 2018).

Maurel, Chloé (2011), “La politique internationale du livre de l'UNECO, 1945-1980”, em C. Hauser et al. (dir.), La Diplomatie par le Livre, Paris, Nouveau Monde Editions, pp. 197-217.

Medeiros, Nuno (2010), Edição e Editores, Lisboa, Imprensa de Ciências Sociais.

Melo, Daniel (2004), A Leitura Pública no Portugal Contemporâneo (1926-1987), Lisboa, Imprensa de Ciências Sociais.

Melo, Daniel (2008), “Estado e sociedade civil em Portugal: leitura pública, educação popular e política cultural (1870-1950)", em A. P. Pita e L. Trindade (coords.), Transformações Estruturais do Campo Cultural Português, 1900-1950, Coimbra, CEIS20-UC, pp. 135-161.

Melo, Daniel (2010), A Leitura Pública na I República, Lisboa / Famalicão, Centro de História da Cultura / Húmus.

Melo, Daniel (2016), “A censura salazarista e as colónias: um exemplo de abrangência”, Revista de História da Sociedade e da Cultura, 16, pp. 475-496, disponível em: https://doi.org/10.14195/1645-2259_16_21 (última consulta em fevereiro de 2018).

Moura, Maria José (2003), "Au Portugal, la constitution d'un réseau”, Bulletin des Bibliothèques de France (BBF), 2, pp. 63-65.

Neves, José (coord.) (2010), Como Se Faz Um Povo, Lisboa, Edições Tinta-da-China e Fundação EDP.

Neves, José Soares (coord.) (2012), Inquérito ao Setor do Livro, Lisboa, Observatório das Atividades Culturais.

Nunes, Henrique Barreto (1996), Da Biblioteca ao Leitor. Estudos sobre a Literatura Pública em Portugal, Braga, Autores de Braga.

Nunes, Henrique Barreto (2008), “Uma revolução silenciosa e tranquila”, Jornal de Letras, Artes e Ideias, 16-29 de janeiro, p. 11.

Osório, Ana de Castro (1928), "A crise do livro português", Seara Nova, 122, pp. 31-33. 
Pereira, Armando Gonçalves (1972), No Ano Internacional do Livro. O Problema do Livro Português, Lisboa, Ática.

Pereira, Helena, e São José Almeida (1998), “As polémicas de Saramago”, Público, 9 de outubro, p. 5.

Perfeito, Paula (2015), “Maria do Rosário Pedreira entre Vistas”, Entrel Vistas (blogue), 27 de maio.

Pina, Sara (1993), “Livrarias ou hipermercados?”, Público, 21 de maio, p. 38 - sup.․․ especial "63. a Feira do Livro".

Rebelo, José (1998), Formas de Legitimação do Poder no Salazarismo, Lisboa, Livros e Leituras.

Ribeiro, Ana Elisa (2007), “José Afonso Furtado: práticas de leitura e letramento digital [entrevista]", Lingua Escrita, 2, pp. 9-16.

Ribeiro, António Pinto (1997), “Cultura e elites: os equívocos fabricados”, Público, 8 de março, p. 34.

Ribeiro, Fernanda (2008), Para o Estudo do Paradigma Patrimonialista e Custodial, Porto, Edições Afrontamento.

Rocha, Natércia (1992), Breve História da Literatura para Crianças, Lisboa, ICALP.

Rouet, François (2007 [2000]), Le Livre, Paris, La Documentation Française.

Sampaio, J. Salvado (1975-76), O Ensino Primário em Portugal, 1911-1969, Lisboa, Instituto Gulbenkian de Ciência, 2 vols.

Santos, A. Nogueira (1949), “As bibliotecas americanas”, Vértice (Coimbra), 7 (66), pp. 111-112.

Santos, Maria de Lourdes Lima dos (coord.) (1998), As Políticas Culturais em Portugal, Lisboa, Observatório das Actividades Culturais.

Santos, Maria de Lourdes Lima dos (coord.), Rui Telmo Gomes, e José Soares Neves (2000), Dinâmicas da Aplicação da Lei do Preço Fixo do Livro, Lisboa, Observatório das Actividades Culturais.

Santos, Maria de Lourdes Lima dos (coord.), Margarida Carvalho, José Soares Neves e Maria João Lima (2007), A Leitura em Portugal, Lisboa, GEPE/ME.

Sepúlveda, Torcato (1993), “O preço fixo do livro, o Estado e os cidadãos”, Público, 21 de maio, p. 23 - sup. especial "63. ․ Feira do Livro".

Simões, João Gaspar (1973), “Crítica literária”, Diário de Notícias, 9 de agosto, p. 13.

Shep, Sydney J. (2008), "Books without borders: the transnational turn in book history", em R. Fraser e M. Hammond (orgs.), Books without Borders, Londres e Nova Iorque, Palgrave, vol. I, pp. 13-37.

Silva, Flamarion Maués P. (2013), Livros que Tomam Partido. A Edição Política em Portugal, 1968-80, São Paulo, Universidade de São Paulo, tese de doutoramento.

Távora, Antónia, Henrique Vaz, e Joaquim Coimbra (2013), “Educação e formação de adultos em Portugal: a história de uma alternância de políticas sem alternativa social", em Atas do VI Seminário Luso-Brasileiro "Educação, Trabalho e Movimentos Sociais - Das Políticas às Lógicas de Ação", Lisboa, IE-UL, pp. 17-28.

Tengarrinha, José (1973), A Novela e o Leitor Português, Lisboa, Prelo Editora.

Teodoro, António (2001), A Construção Política da Educação, Porto, Edições Afrontamento. Traniello, Paolo (1997), La Biblioteca Pubblica, Bolonha, Il Mulino.

Valdemar, António (2015), “Os vizinhos da sala n.o 3 de Santa Engrácia”, Público, 16 de julho, p. 51. 
Werner, Michael, e Bénédicte Zimmermann (2006), “Beyond comparison: ‘histoire croisée' and the challenge of reflexivity", History and Theory, 45 (1), pp. 30-50.

Zaid, Gabriel (2008), Livros de Mais: Ler e Publicar na Era da Abundância, Lisboa, Temas e Debates.

Daniel Melo. Investigador integrado e vice-coordenador do grupo de investigação "Leitura e formas da escrita" do CHAM - Centro de Humanidades, FCSH, Universidade NOVA de Lisboa, Lisboa, Portugal.

E-mail: danielseixasmelo@hotmail.com

Receção: 02 de março de 2018 Aprovação: 28 de novembro de 2018 